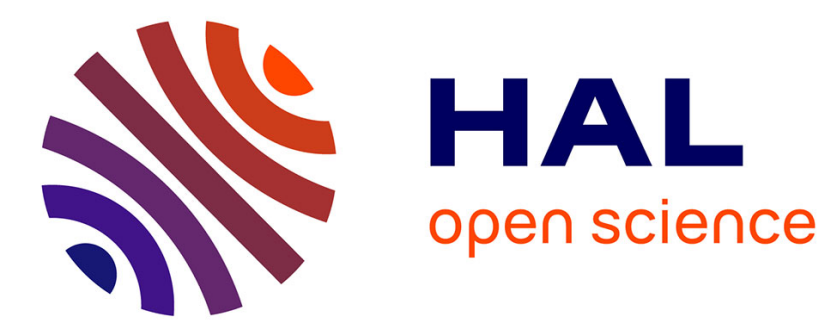

\title{
How does cristallizable rubber use mechanical energy to deform?
}

\author{
Jean-Benoit Le Cam
}

\section{To cite this version:}

Jean-Benoit Le Cam. How does cristallizable rubber use mechanical energy to deform?. Annual Conference and Exposition on Experimental and Applied Mechanics, Jun 2017, Indianapolis, United States. pp.37-42, 10.1007/978-3-319-62899-8_6 . hal-01681196

\section{HAL Id: hal-01681196 \\ https://hal-univ-rennes1.archives-ouvertes.fr/hal-01681196}

Submitted on 16 May 2020

HAL is a multi-disciplinary open access archive for the deposit and dissemination of scientific research documents, whether they are published or not. The documents may come from teaching and research institutions in France or abroad, or from public or private research centers.
L'archive ouverte pluridisciplinaire HAL, est destinée au dépôt et à la diffusion de documents scientifiques de niveau recherche, publiés ou non, émanant des établissements d'enseignement et de recherche français ou étrangers, des laboratoires publics ou privés.

\section{(c)(1)}

Distributed under a Creative Commons Attribution| 4.0 International License 


\title{
How Does Cristallizable Rubber Use Mechanical Energy to Deform?
}

\author{
Jean-Benoît Le Cam
}

\begin{abstract}
Strain-induced crystallization (SIC) is responsible for the hysteresis loop observed in the mechanical response of Natural Rubber (NR). The present paper aims at determining the physical origin of such mechanical energy dissipation. For that purpose, temperature variations are measured by using infrared thermography during cyclic uniaxial tensile tests at ambient temperature. Heat sources (heat power densities) produced or absorbed by the material due to deformation processes are deduced from temperature fields by using the heat diffusion equation. Energy balance performed for each deformation cycle shows that crystallization/melting process does not produce intrinsic dissipation. The crystallization/melting process dissipates mechanical energy without converting it into heat. Hence, the whole dissipated mechanical energy corresponds to energy used by the material to change its microstructure. The demonstration that NR is able to dissipate mechanical energy without converting it into heat explains its ability to resist the crack growth and the fatigue loading.
\end{abstract}

Keywords Infrared thermography $\bullet$ Heat sources $・$ Natural rubber $\bullet$ Strain-induced crystallization

\subsection{Introduction}

Mechanical properties of natural rubber (NR) are mainly related to Strain-Induced Crystallization (SIC) [1]. Especially, SIC enables NR to better resist the crack growth [2,3] and the fatigue [4-7]. Clark et al. were the first to suggest experimentally that the mechanical hysteresis is closely related to SIC [8]. Up to date, the idea that mechanical hysteresis is due to the difference between the kinetics of crystallization and crystallite melting has been widely disseminated, but no further information on the origin of this mechanical dissipation has been provided. Indeed, the formation of a mechanical hysteresis is a complicated process and better understand the energetic nature of the hysteresis loop could provide information of importance on the reinforcement of NR. This paper aims at carrying out energy balances in order to identify and to evaluate the contribution of the different phenomena involved in the formation of the mechanical hysteresis in NR. For that purpose infrared thermography is used to measure the temperature evolution of specimens under quasi-static uniaxial loading at ambient temperature. Heat sources produced or absorbed by the material due to deformation processes are deduced from the temperature variations by using the heat diffusion equation. Energy balances performed at each cycle and at any time during each cycle are finally analyzed to determine the physical origin of the mechanical energy dissipation in NR.

\subsection{Specimen Preparation and Testing Conditions}

The material studied is an unfilled natural rubber (NR) supplied by the "Manufacture Française des pneumatiques Michelin". It is composed of antioxidant (1.9 phr), stearic acid ( $2 \mathrm{phr})$, zinc oxide ( $2.5 \mathrm{phr})$, accelerator (1.6 phr) and sulphur (1.6 phr). The compound was cured for $22 \mathrm{~min}$ at $150{ }^{\circ} \mathrm{C}$. In unfilled NR, SIC is observed in uniaxial tension starting from a stretch $\lambda_{\mathrm{c}}$ of about 4. During unloading, crystallite melting is complete at a lower stretch $\lambda_{\mathrm{m}}$ of about 3 [9-11]. The specimen geometry is $5 \mathrm{~mm}$ in width, $10 \mathrm{~mm}$ in height and $1.4 \mathrm{~mm}$ in thickness. Mechanical tests performed were those reported in the work by

\footnotetext{
J.-B. Le Cam $(\bowtie)$

Université de Rennes 1, Institut de Physique UMR 6251 CNRS/Université de Rennes 1, Campus de Beaulieu,

Bât. 10B, 35042, Rennes Cedex, France

e-mail: jean-benoit.lecam@univ-rennes1.fr
} 
Samaca Martinez, who investigated the thermal and caloric signature of the main phenomena involved in rubber deformation [12-16]. Mechanical loading was applied using a $50 \mathrm{~N}$ Instron 5,543 testing machine. It corresponds to four sets of three cycles, for four increasing maximum stretch ratios: $\lambda_{1}=2, \lambda_{2}=5, \lambda_{3}=6$ and $\lambda_{4}=7.5$. $\lambda_{1}$ was chosen inferior to $\lambda_{c}, \lambda_{2}$ was superior but close to $\lambda_{\mathrm{c}}, \lambda_{3}$ and $\lambda_{4}$ are superior to $\lambda_{\mathrm{c}}$. The signal shape chosen was triangular, to ensure a constant strain rate during loading and unloading. Tests were performed at a loading rate equal to $\pm 100 \mathrm{~mm} / \mathrm{min}$ and $\pm 300 \mathrm{~mm} / \mathrm{min}$. The temperature was measured by using a Cedip Jade III-MWIR infrared camera $(320 \times 240$ pixels, $3.5-5 \mu \mathrm{m})$.

\subsection{Heat Source Calculation from Temperature Field Measurement}

Considering the first and second principles of thermodynamics, assuming that Fourier's law is used to model heat conduction and that the heat conduction is isotropic, the $0 \mathrm{D}$ formulation of the heat diffusion equation writes [17]:

$$
\rho C_{E, V_{K}}\left(\dot{\theta}+\frac{\theta}{\tau}\right)=s
$$

where $\tau$ is considered as a time constant characterizing the heat exchange with ambient air. $\rho$ is the density, $C_{E, V_{K}}$ is the specific heat at constant strain $E$ and internal variables $V_{K}$ and $\theta$ is the temperature variation. This equation is used to process IR images and to calculate homogeneous heat source.

\subsection{Typical Results and Discussion}

\subsubsection{Mechanical Response}

Figure 6.1 presents the mechanical response obtained in terms of the nominal stress versus the stretch. The whole mechanical response is presented in the centre of the figure. The response obtained for each maximum stretch applied is given separately. First of all, whatever the maximum stretch applied, the mechanical cycles have no significant effect on the mechanical response, in the sense that no stress softening is observed. Several comments can be drawn with respect to the maximum stretches $\lambda_{\mathrm{i}}$ applied:

- For cycles at $\lambda_{1}=2$, a very small hysteresis loop is observed. The corresponding power density $\mathrm{P}_{\text {inelastic }}$ is equal to 1.6 $10^{3} \mathrm{~W} / \mathrm{m}^{3}$. The energy contained in the hysteresis loop can be due to intrinsic dissipation and/or thermal dissipation and/or energy used by the material for microstructure changes,

- For cycles at $\lambda_{2}=5$ (the area of the hysteresis loop increases ( $\mathrm{P}_{\text {inelastic }}=4.810^{3} \mathrm{~W} / \mathrm{m}^{3}$ ). The maximum stretch applied exceeds that at which crystallization starts $\left(\lambda_{\mathrm{c}}=4\right)$. Again, both intrinsic dissipation and/or thermal dissipation and/or dissipation due to microstructure changes could contribute to this hysteresis loop. These results are in good agreement with those reported in the literature for unfilled natural rubber studied with X-ray diffraction: a significant hysteresis loop forms if SIC takes place in the material. Classically, the hysteresis loop is explained by the difference in the kinetics of crystallization and crystallite melting [9-11],

- For cycles at $\lambda_{3}=6$, the hysteresis loop is higher than for the previous stretches,

- For cycles at $\lambda_{4}=7.5$, a plateau is observed from $\lambda_{3}=6$ on, followed by a high stress increase. The hysteresis loop is much higher that for the stretch applied just before $\left(4.510^{4} \mathrm{~W} / \mathrm{m}^{3}\right.$ versus $1.310^{4} \mathrm{~W} / \mathrm{m}^{3}$ for the corresponding power density). As assumed by Flory [18] and highlighted by Toki et al. [9] and Trabelsi et al. [10], once crystallization occurs, relaxation is induced in the amorphous phase. The plateau observed is a manifestation of this relaxation. For higher stretches, crystallites act as fillers and strongly reinforce the material stiffness, which explains the high increase in the nominal stress. It should be noted that tensile test performed at the higher loading rate does not change the hysteresis area, meaning that thermal dissipation is negligible.

To summarize, the hysteresis loop can be due to intrinsic dissipation and/or microstructure changes only. Distinguishing these two types of energy dissipation is a main topic. The former is the signature of damage, the latter not, which is of paramount importance to explain the cyclic behaviour of NR. The next step is dedicated to the determination of the intrinsic dissipation over each cycle, i.e. the part of the mechanical energy converted into heat. 

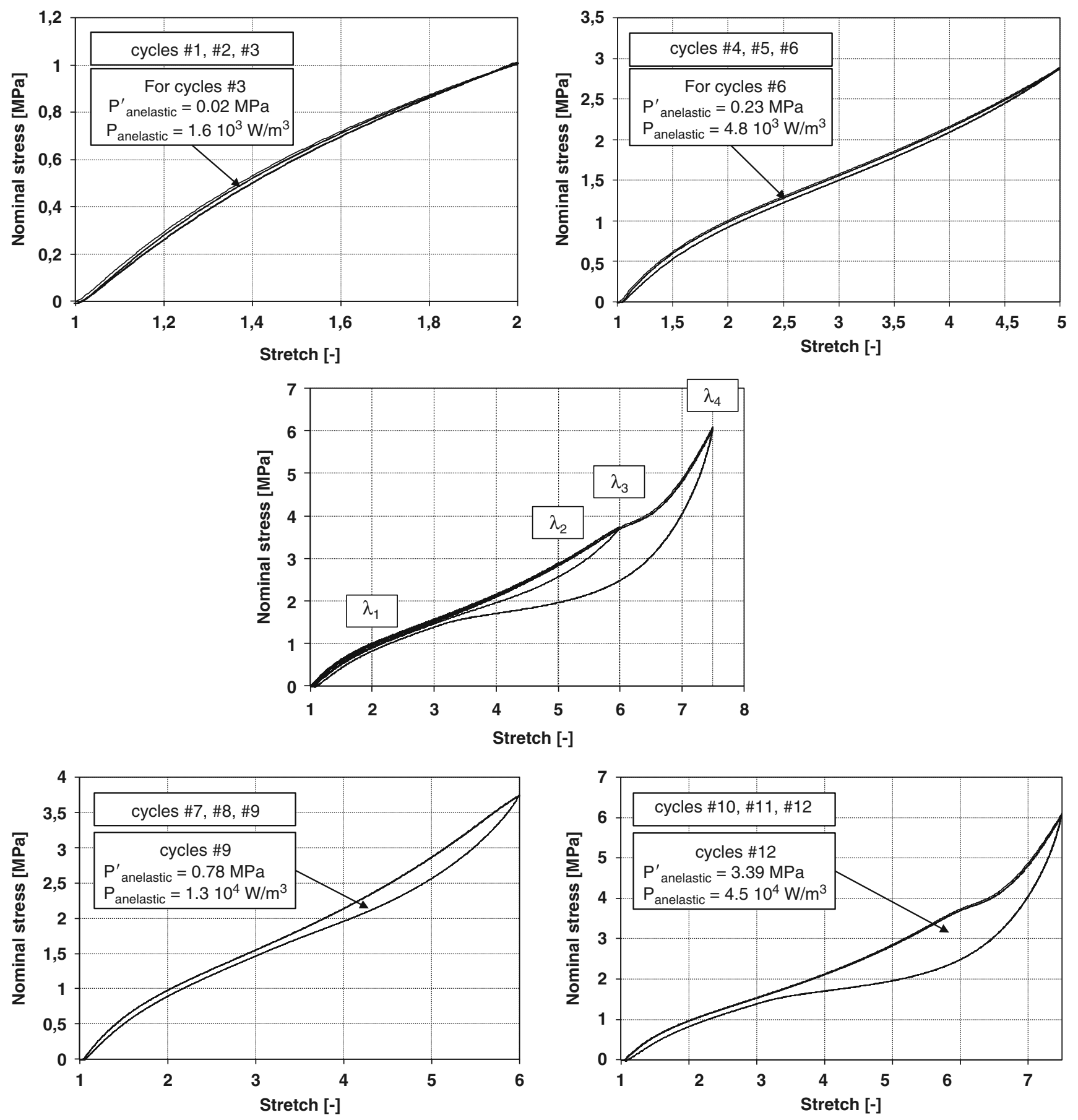

Fig. 6.1 Mechanical response

\subsubsection{Calorimetric Response and Intrinsic Dissipation}

Calorimetric response of NR has been established by using the simplified formulation of the heat diffusion. It should be noted that parameter $\tau$ was identified from natural return at ambient temperature for different stretches. Its expression was $\tau(\lambda)=40.48-3.25 \lambda$. Figure 6.2 gives the heat source as a function of the stretch during the cycles of each set of maximum stretch, for a loading rate equal to $\pm 100 \mathrm{~mm} / \mathrm{min}$. Integrating the heat source over one cycle provides the energy corresponding to the intrinsic dissipation $\mathrm{W}_{\text {intrinsic }}$. The intrinsic dissipation $\mathrm{d}_{1}$ is obtained by dividing $\mathrm{W}_{\text {intrinsic }}$ by the 


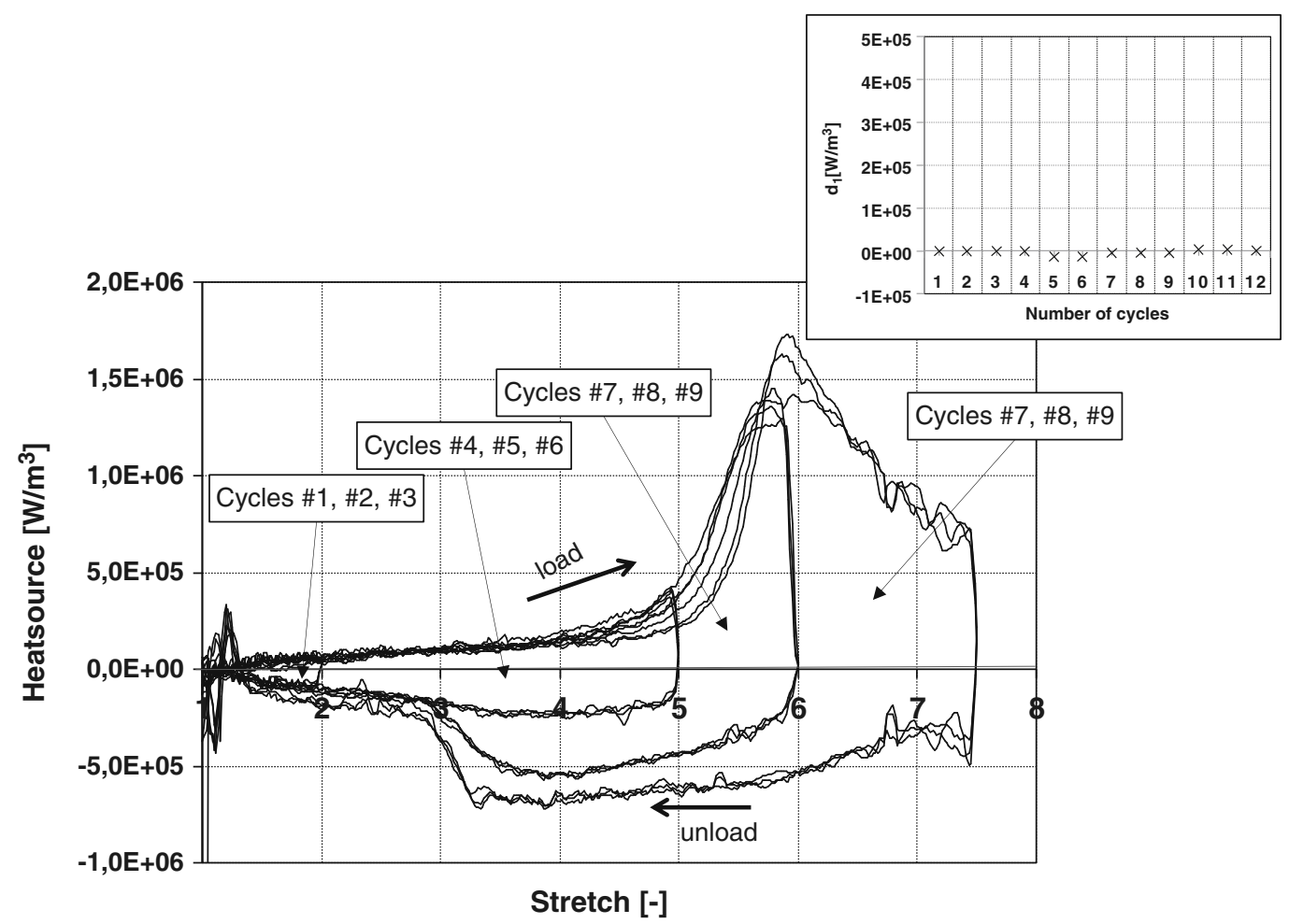

Fig. 6.2 Heat sources

considered cycle duration. Typically in polymers, $\mathrm{d}_{1}$ is the calorimetric signature of viscosity or damage (see the calorimetric characterization of viscosity and stress softening induced by carbon black fillers in SBR [13]).

Several comments can be drawn from this figure, with respect to the maximum stretch applied:

- For cycles at $\lambda_{1}=2$, the heat source is positive during loading and increases with the stretch. During unloading, the heat source is negative. This is due to entropic elasticity that is preponderant in the thermal response of the stretched material. The load-unload evolution is symmetrical, meaning that the heat produced during loading phase is equal to the heat source absorbed during unloading phase. Therefore, no intrinsic dissipation is detected,

- For cycles at $\lambda_{2}=5$, the heat source evolutions for loading and unloading are not symmetrical anymore. This cannot be explained by entropic elasticity. During loading, the heat source evolves in a quasi-linear manner until reaching a stretch close to 4 . This evolution can be explained by entropic coupling. The dissymmetry takes place for stretches higher than 4 , the stretch level at which SIC starts. Moreover, the areas under the curves during loading and unloading are equal, meaning that no intrinsic dissipation is produced (see the diagram at the top, on the right side). Consequently, the only explanation for the dissymmetry is the occurrence of crystallization during loading, and a difference in the kinetics of crystallization and crystallite melting. This is in a good agreement with studies reported in the literature [9-11]. Concerning the stressstrain curve, a hysteresis loop larger than for $\lambda_{1}=2$ is observed. If thermal dissipation and intrinsic dissipation are negligible, this means that the area of the hysteresis loop corresponds to mechanical energy used by the material for crystallization and crystallite melting,

- For cycles at $\lambda_{3}=6$, the heat source first increases with the same slope as before, and then strongly increases starting from a stretch close to 4 . The loading-unloading dissymmetry level of the heat source curves increases. Again, the heat produced is equal to the heat absorbed, meaning that no mechanical dissipation is detected,

- For cycles at $\lambda_{4}=7.5$, the phenomena are similar to those observed above, except for the evolution of the heat source for stretch ratios superior to 6 . Indeed, during the loading phase, instead of increasing continuously, the heat source decreases from $\lambda_{3}=6$. This means that heat due to crystallization could continue to be produced (it remains positive), but at a lower rate, and/or that larger energetic effects take place. 

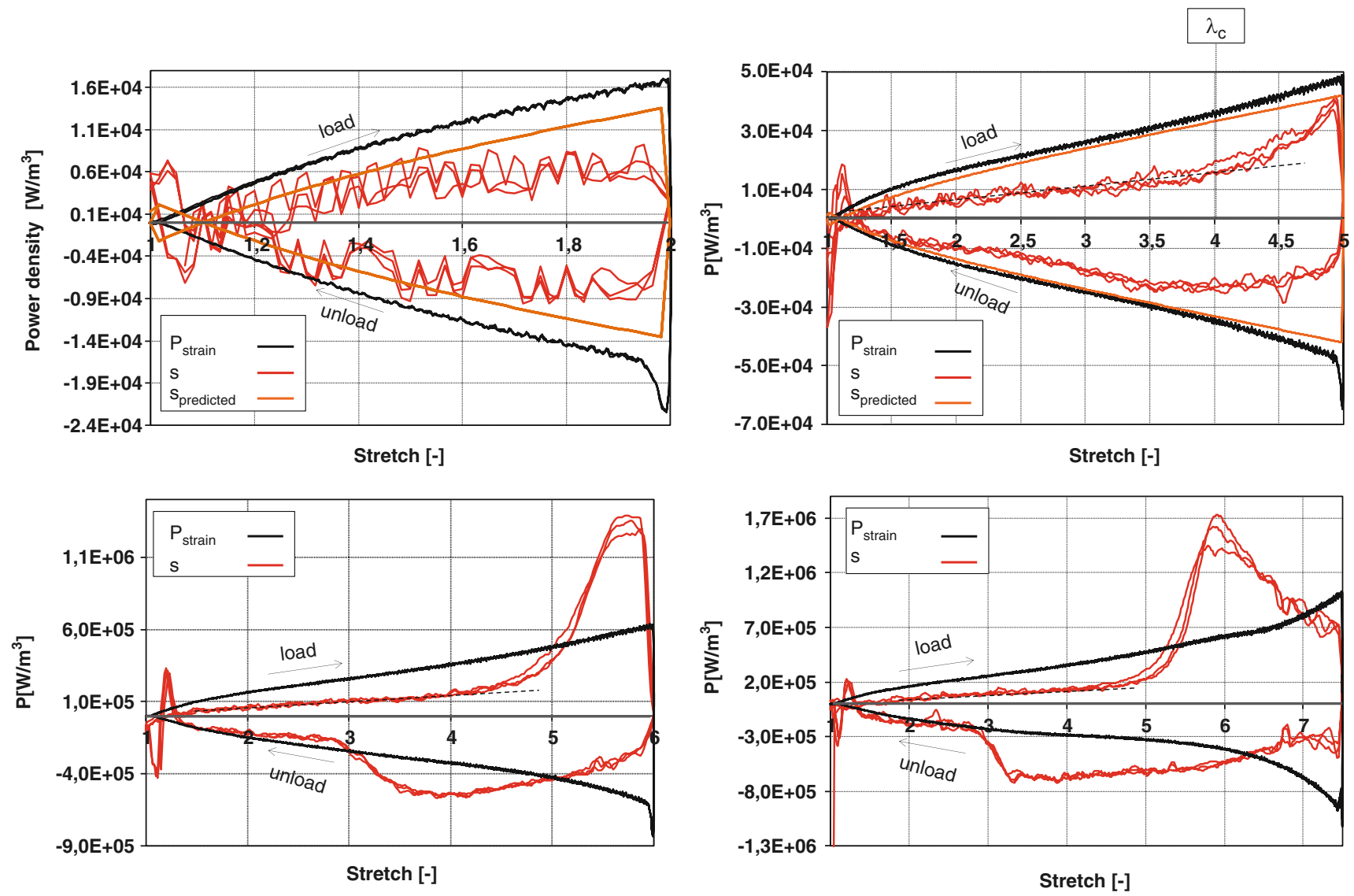

Fig. 6.3 Strain power density and heat sources for the different sets at increasing maximum stretches

\subsubsection{Mechanical Energy Is Used for Structure Changes}

Energy balance performed over each cycle highlights that NR deformation does not induce detectable intrinsic dissipation during mechanical cycles. The hysteresis area corresponds therefore to the energy used by the material to change its microstructure. It does not involve heat. Hence, the question is to define why the material needs this energy and if the energy dissipated is the same during loading and unloading. To answer this question, the energy balance is carried out at any time during the deformation cycle, by comparing the strain power density $\mathrm{P}_{\text {strain }}$ and the heat power density (heat source) $\mathrm{s}$. Fig. 6.3 presents the evolution of $\mathrm{P}_{\text {strain }}$ (in black color) and $\mathrm{s}$ (in red color) for each set of maximum stretch.

For $\lambda_{1}=2<\lambda_{c}$, these powers are not equal $\left(\mathrm{P}_{\text {strain }}>\mathrm{s}\right)$. This means that NR does not behave as a purely entropic material. Internal energy also changes [19], which contributes to the calorific response. In this figure, the prediction of heat sources due to both entropy and internal energy is plotted in orange color (for the first two maximum stretch levels applied). Results show that the model fits well the level of thermoelastic inversion and the heat sources until to reach a stretch of about 1.6. This means first that the calorific response is strongly influenced by energetic elasticity, even though entropic elasticity is preponderant. Second, from a stretch equal to 1.6 on, the experimental heat sources are lower than the prediction. This means that the corresponding energy is used by the material to change its microstructure. This also explains which a hysteresis loop is observed for maximum stretches inferior to that at which SIC starts. Note that the model used to predict the heat source is not suitable at large deformations and when crystallization occurs, but it gives a realistic tendency before crystallization starts. For $\lambda_{3}=6>\lambda_{\mathrm{c}}$, a strong increase in the heat source is observed from $\lambda_{2}=5$ on, and $\mathrm{P}_{\text {strain }}<\mathrm{s}$, with $\mathrm{d}_{1}=0 \mathrm{~W} / \mathrm{m}^{3}$. Hence, the whole additional heat source is due to the crystallization. For $\lambda_{4}=7.5$, the same analysis can be drawn except for the change in the heat source curve slope from $\lambda_{3}=6$ on, which has already been discussed previously. 


\subsection{Conclusion}

Strain-induced crystallization (SIC) is responsible for the hysteresis loop observed in the mechanical response NR. The inelastic energy contained in the mechanical hysteresis corresponds neither to intrinsic dissipation nor thermal dissipation. This energy is used by the material to change its microstructure. Calorimetric analyses have shown that crystallization/melting process does not produce intrinsic dissipation, i.e. crystallite melting absorbs the entire heat produced by SIC. As thermal dissipation was negligible, the crystallization/melting process does not convert mechanical energy into heat, neither through intrinsic nor thermal dissipation. The mechanical energy brought to the material is therefore used to change microstructure. The demonstration that NR is able to dissipate mechanical energy without converting it into heat explains its ability to resist the crack growth and the fatigue loading.

Funding Information Author acknowledges the "Manufacture Française des pneumatiques Michelin" for supporting this study. Author thanks J.R. Samaca Martinez, most of the results presented in the paper were obtained during his PhD Thesis. X. Balandraud, E. Toussaint, J. Caillard and D. Berghezan are acknowledged for the fruitful discussions.

\section{References}

1. Huneau, B.: Rubber Chem. Technol. 84, 425-452 (2011)

2. Lee, D.J., Donovan, J.A.: Rubber Chem. Technol. 60, 910-923 (1987)

3. Lake, G.J.: Rubber Chem. Technol. 68, 435-460 (1995)

4. Cadwell, S.M., Merril, R.A., Sloman, C.M., Yost, F.L.: Ind. Eng. Chem.. (reprinted in Rubber Chem. and Tech. 1940;13:304-315). 12, 19-23 (1940)

5. Beatty, J.R.: Rubber Chem. Technol. 37, 1341-1364 (1964)

6. Saintier, N.: Prévisions de la durée de vie en fatigue du NR, sous chargement multiaxial. Thèse de doctorat, École Nationale Supérieure des Mines de Paris (2000)

7. Le Cam, J.-B., Huneau, B., Verron, E.: Int. J. Fatigue. 52, 82-94 (2013)

8. Clark, G.L., Kabler, M., Blaker, E., Ball, J.M.: Hysteresis in crystallization of stretched vulcanized rubber from x-ray data. Ind. Eng. Chem. 32, 1474-1477 (1940)

9. Toki, S., Fujimaki, T., Okuyama, M.: Strain-induced crystallization of natural rubber as detected real-time by wide-angle x-ray diffraction technique. Polymer. 41, 5423-5429 (2000)

10. Trabelsi, S., Albouy, P.-A., Rault, J.: Crystallization and melting processes in vulcanized stretched natural rubber. Macromolecules. 36, 7624$7639(2003)$

11. Le Cam, J.-B., Toussaint, E.: Macromolecules. 41, 7579-7583 (2008)

12. Samaca Martinez, J.R., Le Cam, J.-B., Balandraud, X., Toussaint, E., Caillard, J.: Thermal and calorimetric effects accompanying the deformation of natural rubber. Part 1: thermal characterization. Polymer. 54, 2717-2726 (2013)

13. Samaca Martinez, J.R., Le Cam, J.-B., Balandraud, X., Toussaint, E., Caillard, J.: Polym. Test. 32, 835-841 (2013)

14. Samaca Martinez, J.R., Le Cam, J.-B., Balandraud, X., Toussaint, E., Caillard, J.: Thermal and calorimetric effects accompanying the deformation of natural rubber. Part 2: quantitative calorimetric analysis. Polymer. 54, 2727-2736 (2013)

15. Samaca Martinez, J.R., Le Cam, J.-B., Balandraud, X., Toussaint, E., Caillard, J.: J. Eur. Polym. J. 55, $98-107$ (2014)

16. Le Cam, J.-B., Samaca Martinez, J.R., Balandraud, X., Toussaint, E., Caillard, J.: Exp. Mech. 55, 771-782 (2015)

17. Chrysochoos, A., Louche, H.: Thermal and dissipative effects accompanying luders band propagation. Mat. Sci. Eng. A. 307, 15-22 (2001)

18. Flory, P.J.: Thermodynamics of crystallization in high polymers. I. Crystallization induced by stretching. J. Chem. Phys. 15, 397-408 (1947)

19. Treloar, L.R.G.: The elasticity and related properties of rubbers. Rep. Prog. Phys. 36, 755 (1973) 